\title{
The relationships between health-related behaviours in the Canadian adult population
}

\author{
Adriana N. Mudryj ${ }^{1 *}$, Natalie D. Riediger ${ }^{1,2}$ and Andrea E. Bombak ${ }^{3}$
}

\begin{abstract}
Background: Health-related behaviours such as physical inactivity, low fruit and vegetable intake, smoking, alcohol use, and inadequate sleep are significant predictors of adverse health outcomes. Health promotion strategies often focus on one behavior, though research suggests health-related behaviours tend to co-occur. The purpose of this study is to describe the relationships between health-related behaviours in the Canadian adult population.

Methods: Data from cycles 3 (2012-2013) and 4 (2014-2015) of the Canadian Health Measures Survey were pooled to describe health-related behaviours (current smoking status, high-risk alcohol use, fruit and vegetable intake, inadequate sleep, and physical activity) among adults according to sex, age group, household education, and income adequacy. Logistic regression was used to test for relationships between health-related behaviours.

Results: Findings indicated that adverse health-related behaviours co-occur frequently, with approximately half of Canadians reporting two or more adverse health-related behaviours. Overall, Canadian men were more likely to report adverse health-related behaviours compared to women, with the exception of inadequate sleep. Smoking status, fruit and vegetable intake, sleep and physical activity exhibited an income and education gradient. Sexbased patterns in grouping of behaviours were present such that adverse health-related behaviours were associated with current smoking among men and with high-risk alcohol use among women.
\end{abstract}

Conclusion: Our findings suggest that health-related behaviours should be considered in both isolation and combination when designing intervention strategies. Sex-specific patterns of how these behaviours co-occur must also be taken into account.

Keywords: Health behaviour, Canadian health measures survey, Tobacco, Alcohol use, Fruit and vegetable, Physical activity, Sleeping habits, Diet

\section{Background}

Health-related behaviours such as physical activity, fruit and vegetable intake, smoking, alcohol use, and sleeping habits are significant and, presumably, modifiable behavioural predictors of numerous health outcomes like type 2 diabetes, cardiovascular disease, and cancer [1]. Although health promotion strategies often focus on isolated healthrelated behaviors, many health-related behaviours typically do not occur as separate behaviours, but co-occur together [2]. Further, research in other countries suggests

\footnotetext{
* Correspondence: adriana.mudryj@umanitoba.ca

${ }^{1}$ Department of Food and Human Nutritional Sciences, Faculty of Food and Agricultural Sciences, University of Manitoba, 402 Human Ecology, Winnipeg, Canada

Full list of author information is available at the end of the article
}

that the majority of individuals exhibit two or more adverse health-related behaviours [3], which aggregate more frequently in certain population subgroups [4].

Understanding the relationships among adverse healthrelated behaviours is important and may provide valuable information for designing appropriate intervention programs. For example, smoking has been shown to have the most bearing on other adverse health-related behaviours [5]. Smoking has been consistently associated with alcohol use at levels exceeding the national guidelines [6]; low intake of fruits and vegetables; significantly higher intakes of energy, fat, cholesterol, and alcohol; and lower intakes of fibre, polyunsaturated fats, and antioxidant vitamins [7]. Similarly, low physical activity has been associated with

(c) The Author(s). 2019 Open Access This article is distributed under the terms of the Creative Commons Attribution 4.0 International License (http://creativecommons.org/licenses/by/4.0/), which permits unrestricted use, distribution, and 
not eating fruit on the previous day as well as increased alcohol use among U.S. adolescents [8]. Research also suggests that men and individuals with low socioeconomic status are more likely to report co-occurring adverse health-related behaviours $[4,9]$.

The co-occurrence of health-related behaviours has exhibited geographic patterns according to neighbourhood socioeconomic status [10]. Social and economic inequities have a strong impact on health and well-being. The social determinants of health, including income, support networks, education, and colonialism influence health-related behaviours in a multitude of ways, affecting both mental and physical health [11]. Despite a growing body of literature examining the co-occurrence of health-related behaviours, there is little consensus about which behaviours occur together in certain subgroups, for example, sex. Moreover, the co-occurrence of health-related behaviours may also differ across time and contexts. As such, a current examination in the Canadian context is needed. This evidence could inform current intervention and implementation strategies to address risk of non-communicable disease by identifying populations who report multiple adverse health-related behaviours, and examining the role of social determinants of health in influencing singular and combined health-related behaviours. Therefore, the purpose of this study is to describe health-related behaviours in the Canadian adult population according to age, sex, income adequacy, and household education, as well as describe the associations between health-related behaviours.

\section{Methods}

\section{Study design and sample}

This study used data from the Canadian Health Measures Survey (CHMS), cycles 3 (2012-2013) and 4 (2014-2015). The CHMS is a comprehensive, selfreported direct health measures survey that included blood, urine, and anthropometric measures, as well as a food frequency questionnaire (FFQ) [12]. Cycles 3 and 4 surveyed 5785 and 5794 respondents, with response rates of 51.7 and $53.7 \%$, respectively. A full description of the household and individual response rates for each survey are fully described elsewhere [13, 14]. Participants $<18$ years old and pregnant women were not included in our sample, excluding 2396 in cycle 3 and 2394 in cycle 4 (total sample excluded, $n=4790$ ). A total of 6789 respondents met our inclusion criteria.

\section{Measures}

Five self-reported health-related behaviours were included in the present study: current smoking, alcohol use, fruit and vegetable intake, inadequate sleep, and physical activity. Smoking was dichotomized as current, including occasional or daily, versus non -smoker (which included former smokers). Alcohol use was dichotomized into low and high-risk use, with high-risk defined as $\geq 5$ drinks for men or $\geq 4$ drinks for women on one occasion $\geq 2$ times per month over the past year OR consuming alcohol every day in the past year [15]. Fruit and vegetable intake, obtained from the Food Frequency Questionnaire, was deemed adequate at $\geq 4$ servings per day (excluding potatoes and juice) and inadequate when $<4$ servings per day were consumed [16]. Inadequate sleep was dichotomized as $\leq 6 \mathrm{~h} /$ day ('short duration') or $\geq 10 \mathrm{~h} /$ day ('long duration') OR two or more of the following: having trouble going to sleep or staying asleep most or all of the time; never or rarely feeling refreshed by sleep; or finding it difficult to stay awake during normal waking hours when you want most or all of the time [17]. Physical activity was dichotomized as adequate and inadequate levels, based on an average of $\geq 30 \mathrm{~min}$ of low, moderate or vigorous physical activity on at least 5 days per week using results from an activity-monitoring device. Device data were blind to respondents while they wore it. Additionally, a "valid" day was defined as $>10 \mathrm{~h}$ of monitor wear time. Respondents with at least 4 valid days were retained for analyses in the CHMS [6]. The number of adverse health-related behaviours was summed for each respondent, providing a value between 0 and 5 , and dichotomized as $\geq 3$ adverse health-related behaviours and $<3$ behaviours.

The following socioeconomic variables were included: sex, age group, highest level of education (household), and income adequacy. Sex was dichotomized as man and women; notably the CCHS did not have any other options. Given this omission, and the survey's explicit use of the term sex, we consider this a measure of a respondent's sex (i.e. their physiological and physical characteristics based on chromosomal complement) and not their gender (socially constructed roles and identities) [18]. Age was grouped as 18-29, 30-39, 40-49, 50-59 and $\geq 60$ years. Highest level of household education was grouped as: less than secondary school graduation, secondary school graduation, and post-secondary graduation. Income adequacy was categorized into 4 groups as defined by Statistics Canada [19] based on total household income and number of individuals in the household, and was grouped as: lowest income group, lower middle income group, upper middle income group, and highest income group. Notably, Statistics Canada provides imputed values for household income due to the high percentage of missing values, as previously described [12].

\section{Analysis}

All data analyses were performed using SPSS Statistics Software (IBM International) and STATA (StataCorp) 
and conducted in the secure location of the Manitoba Research Data Centre. Significance was set at $p<0.05$. We conducted a sex and gender-based analysis (SGBA) where sample sizes allowed. Different disciplines have grappled with how to define, describe, and operationalize the complexity of sex and gender [20-22]. Our usage of sex and gender is in line with those proposed by the Canadian Institutes of Health Research [18] and the Institute of Medicine [23]. Sex differences refer to the physiological and biological differences between males and females at the cellular and organ levels, while a combination of social, identity-related, environmental and cultural influences contribute to gender differences. Briefly, a SGBA means considering both sex and gender in the analysis and interpretation of the results, including stratifying results by sex and considering both sex and gender in the interpretation of the findings [24]. While the CCHS data only includes a sex variable (not gender), many of the findings are interpreted primarily via socially-based gender roles.

Participant survey weights and the bootstrapping method were used in all the data analyses for this study. This approximation technique is recommended by Statistics Canada for use with the CHMS to estimate standard errors, coefficients of variation and confidence intervals, which apply to population-level estimates. The bootstrapping method was used to estimate the distributions from a sample's statistics and involves the selection of random samples known as replicates, and the calculation of the variation in the estimates from replicate to replicate [25]. This technique also mitigates the effect of non-response. There were minimal missing data; as such, no additional techniques were used to account for missing data. Response rates for the health-related behaviours are as follows: current smoking $(99 \%)$, high-risk alcohol use (83\%), inadequate sleep (99\%), fruit and vegetable intake (100\%), and inadequate physical activity (90\%).

First, health-related behaviours were described as proportions with standard error (SE), according to previously mentioned demographic factors. Chi-square tests were used to test for differences in each health-related behaviour according to sex, age group, education, and income adequacy. Second, we report number of adverse health-related behaviours. Third, we used logistic regression to test for predictors (age, sex, education, and income) of reporting $\geq 3$ adverse health-related behaviours. Fourth, cross-tabulations were conducted for each combination of health-related behaviours. For example, we described the proportion of people who currently smoke who also report high-risk alcohol use, inadequate fruit and vegetable intake, low physical activity, or inadequate sleep. Finally, logistic regression was used to test for relationships of all health-related behaviours with each other. For example, all health-related behaviours with the exception of physical activity were examined as predictors of inadequate physical activity. Separate models for each sex resulted in ten models, or five healthrelated behaviours as outcomes (i.e. models) per sex.

Project approval was granted by Statistics Canada, which allowed project members to access the data. Research for this study was conducted at the Manitoba Research Data Centre and was consistent with Research Ethics Board Requirements. Data were analyzed in a secure environment and all output was vetted to prevent release of any identifying information.

\section{Results}

\section{Health-related behaviours by demographic factors}

Prevalence of reported health-related behaviours are summarized in Table 1. The most common healthrelated behaviour was low fruit and vegetable consumption (69.1\%). Inadequate sleep was the second most common adverse health-related behaviour reported (36.0\%), followed by high-risk alcohol use (26.6\%), current smoking (22.1\%), and low physical activity (17.9\%). Overall, men were more likely to report adverse health-risk behaviours than women, with the exception of inadequate sleep. Household education and income adequacy were significantly associated with all healthrisk behaviours, with the exception of high-risk alcohol use.

\section{Number of co-occurring health-related behaviours}

Overall, $30.9 \%$ of Canadians reported two adverse health-related behaviours, and $21.2 \%$ report three or more adverse behaviours. One-quarter of men reported three or more adverse health-related behaviours compared to $16.8 \%$ of women (Fig. 1). Specifically, women were $40 \%$ less likely to report $\geq 3$ adverse health-related behaviours compared to men $(p<0.01)$, independent of age group, education, and income (Table 2). Younger age, lower level of education, and lower income adequacy were also significantly associated with increased odds of reporting $\geq 3$ health-related behaviours.

\section{Association of health-related behaviours}

Respondents who smoked demonstrated the highest proportions of inadequate sleep, low physical activity, highrisk alcohol use, and low fruit and vegetable consumption as compared to respondents who reported any other adverse health-related behaviour (Table 3). For example, while the overall prevalence of high-risk alcohol use was $26.0 \%$, among current smokers, $38.2 \%$ reported high-risk alcohol use.

For men, smoking was a significant predictor of all other health-risk behaviours. Other than smoking, no other health-related behaviours were significantly associated with each other, independent of other health-related 
Table 1 Health-related behaviours according to demographic and socioeconomic variables

\begin{tabular}{|c|c|c|c|c|c|c|}
\hline Demographic (n) & $\begin{array}{l}\text { Current } \\
\text { smoker }\end{array}$ & $\begin{array}{l}\text { High-risk } \\
\text { alcohol use }^{\text {a }}\end{array}$ & $\begin{array}{l}\text { Inadequate } \\
\text { sleep }\end{array}$ & $\begin{array}{l}\text { Inadequate physical } \\
\text { activity }\end{array}$ & $\begin{array}{l}<4 \text { servings of fruit \& } \\
\text { vegetables per day }\end{array}$ & $\begin{array}{l}\geq 3 \text { adverse } \\
\text { behaviours }\end{array}$ \\
\hline \multicolumn{7}{|l|}{ Sex } \\
\hline Male (3360) & $26.1(1.2)$ & $32.7(1.8)$ & $35.5(1.5)$ & $20.1(1.4)$ & $75.9(1.4)$ & $25.5(1.3)$ \\
\hline Female (3429) & $18.2(1.3)$ & $20.3(1.7)$ & $36.5(1.5)$ & $15.8(0.9)$ & $62.3(1.7)$ & $16.8(1.0)$ \\
\hline$p$-value & $<0.001$ & $<0.001$ & 0.619 & 0.006 & $<0.001$ & $<0.001$ \\
\hline \multicolumn{7}{|l|}{ Age (y) } \\
\hline 18-29 (1139) & $26.3(2.3)$ & $31.8(3.3)$ & $34.4(2.5)$ & $26.8(2.1)$ & $73.4(2.0)$ & $26.3(2.3)$ \\
\hline $30-39(1443)$ & $25.7(3.6)$ & $26.9(3.3)$ & $33.1(2.5)$ & $20.6(2.5)$ & $66.9(2.6)$ & $22.7(2.1)$ \\
\hline $40-49(1342)$ & $24.4(2.2)$ & $24.6(2.6)$ & $35.2(2.9)$ & $16.9(2.3)$ & $67.4(2.2)$ & $22.9(2.6)$ \\
\hline 50-59 (803) & $22.3(1.6)$ & $24.8(2.4)$ & $43.6(3.1)$ & $14.6(2.3)$ & $69.9(2.8)$ & $20.7(1.9)$ \\
\hline $60+(2062)$ & $13.2(0.9)$ & $24.6(1.6)$ & $34.1(1.8)$ & $11.3(0.7)$ & $67.3(1.9)$ & $13.0(0.8)$ \\
\hline$p$-value & $<0.001$ & 0.178 & 0.057 & $<0.001$ & 0.165 & $<0.05$ \\
\hline \multicolumn{7}{|l|}{ Household Education } \\
\hline < Secondary School (476) & $40.0(4.1)$ & $33.0(5.3)$ & $47.9(4.4)$ & $29.5(4.9)$ & $80.3(3.9)$ & $38.0(3.2)$ \\
\hline $\begin{array}{l}\text { Secondary School Graduation } \\
\text { (951) }\end{array}$ & $34.5(3.5)$ & $29.7(3.2)$ & $44.4(3.4)$ & $21.1(2.3)$ & $73.2(2.3)$ & $31.7(3.3)$ \\
\hline $\begin{array}{l}\text { Post-Secondary School } \\
\text { Graduation }^{\mathrm{b}}(5124)\end{array}$ & $18.1(1.0)$ & $25.2(1.8)$ & $33.1(1.4)$ & $16.0(0.9)$ & $67.4(1.4)$ & $17.0(1.2)$ \\
\hline$p$-value & $<0.001$ & 0.168 & $<0.01$ & $<0.01$ & $<0.01$ & $<0.001$ \\
\hline \multicolumn{7}{|l|}{ Income Adequacy ${ }^{c}$} \\
\hline Lowest (464) & $42.6(4.9)$ & $32.2(7.3)$ & $39.6(5.0)$ & $27.9(4.6)$ & 77.0 (3.6) & $32.9(2.1)$ \\
\hline Lower Middle (1051) & $32.7(3.2)$ & $34.7(3.4)$ & $43.1(2.9)$ & $23.9(2.6)$ & $69.1(3.4)$ & $29.8(1.9)$ \\
\hline Upper Middle (1941) & $23.0(2.0)$ & $27.0(2.3)$ & $37.9(1.7)$ & $16.9(1.7)$ & $72.3(2, .0)$ & $21.9(1.9)$ \\
\hline Highest (3333) & $16.2(1.2)$ & $26.3(1.8)$ & $32.6(1.7)$ & $17.9(1.5)$ & $66.4(1.3)$ & $16.9(1.8)$ \\
\hline p-value & $<0.001$ & 0.687 & $<0.05$ & $<0.05$ & $<0.05$ & $<0.001$ \\
\hline
\end{tabular}

\footnotetext{
Note: $\mathrm{SE}=$ standard error
}

${ }^{a}$ High risk use was defined as $\geq 5$ drinks (males) and $\geq 4$ drinks (females) on one occasion $\geq 2$ times per month over the past year OR consuming alcohol every day in the past year;

b Includes trade certificate or diploma, college, CEGEP or other non-university certificate or diploma, university certificate or diploma below the bachelor's level bachelor's degree, university certificate/diploma/degree above the bachelor's level

${ }^{c}$ Classifies total household income into 4 categories based on total household income and the number of people living in the household

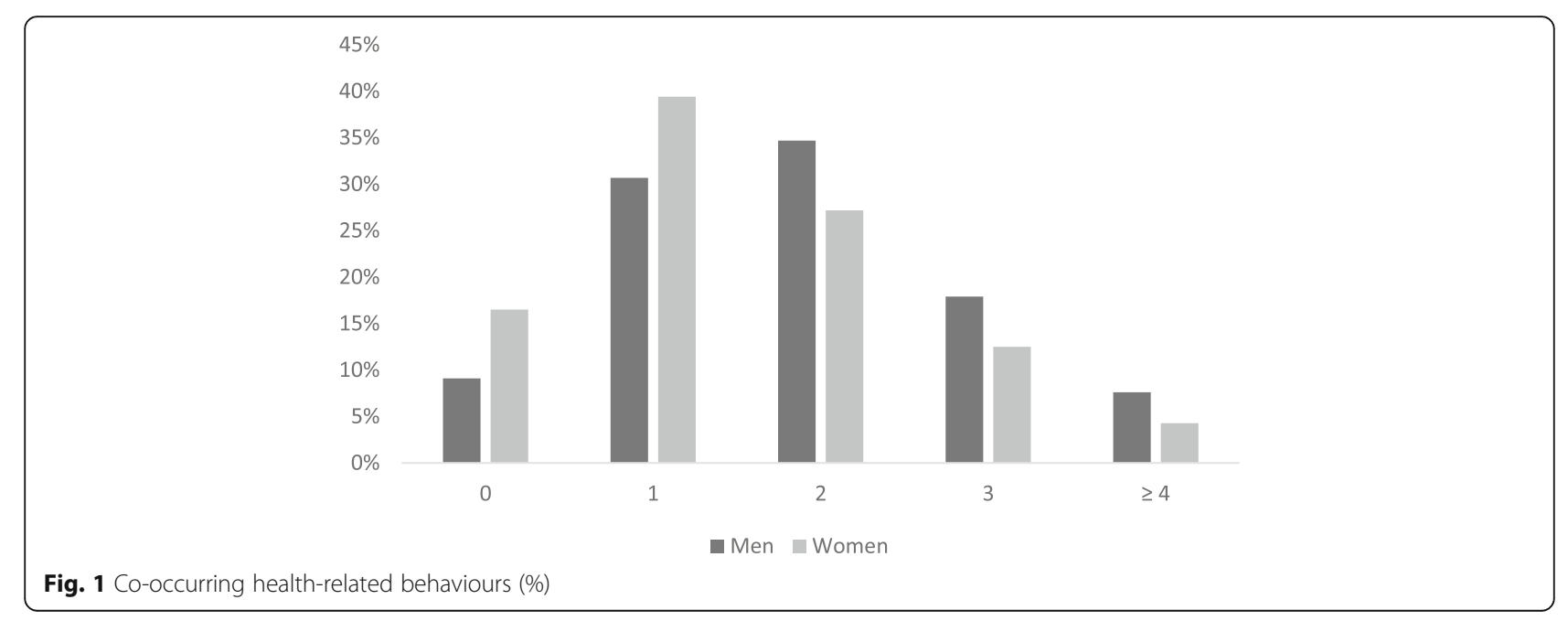


Table 2 Odds ratio ( $95 \% \mathrm{Cl}$ ) of $\geq 3$ adverse health-related behaviours

\begin{tabular}{|c|c|c|c|}
\hline & Men and women & Men & Women \\
\hline \multicolumn{4}{|l|}{ Sex } \\
\hline Men & Reference & & \\
\hline Women & $0.61(0.48-0.76)^{* *}$ & & \\
\hline \multicolumn{4}{|l|}{ Age $(y)$} \\
\hline $18-29$ & Reference & Reference & Reference \\
\hline $30-39$ & $0.84(0.58-1.22)$ & $1.05(0.60-1.85)$ & $0.64(0.33-1.27)$ \\
\hline $40-49$ & $0.96(0.63-1.46)$ & $1.26(0.66-2.39)$ & $0.67(0.40-1.13)$ \\
\hline $50-59$ & $0.61(0.42-0.89)^{*}$ & $0.62(0.36-1.07)$ & $0.63(0.36-1.12)$ \\
\hline$\geq 60$ & $0.36(0.24-0.54)^{* *}$ & $0.49^{*}(0.26-0.93)$ & $0.22(0.14-0.35)^{* * *}$ \\
\hline \multicolumn{4}{|l|}{ Household Education } \\
\hline$<$ Secondary School & Reference & Reference & Reference \\
\hline Secondary School Graduation & $0.60(0.36-1.01)$ & $0.76(0.41-1.39)$ & $0.44(0.16-1.25)$ \\
\hline Post-Secondary School Graduation & $0.30(0.20-0.46)^{*}$ & $0.43(0.24-0.75)^{* *}$ & $0.19(0.07-0.47)^{* *}$ \\
\hline \multicolumn{4}{|l|}{ Income Adequacy } \\
\hline Lowest & Reference & Reference & Reference \\
\hline Lower Middle & $0.83(0.46-1.48)$ & $0.77(0.33-1.73)$ & $0.90(0.32-2.50)$ \\
\hline Upper Middle & $0.67(0.38-1.20)$ & $0.69(0.28-1.68)$ & $0.64(0.22-1.84)$ \\
\hline Highest & $0.52(0.31-0.86)^{*}$ & $0.52(0.27-0.99)^{*}$ & $0.49(0.18-1.38)$ \\
\hline
\end{tabular}

${ }^{*} \mathrm{p}<0.05 ;{ }^{* *} \mathrm{p}<0.01 ;{ }^{* * *} p<0.001$

behaviours among men. Among Canadian women, highrisk alcohol use was associated with increased odds of smoking, inadequate sleep, low physical activity and low fruit and vegetable consumption (Table 4). Among women, smoking was only significantly associated with high-risk alcohol use.

\section{Discussion}

The current study identified discernible patterns of health-related behaviours in the Canadian adult population. Findings indicated that about $21 \%$ of Canadian adults report at least three adverse health-behaviours, which is consistent with other research in the general Canadian adult population [3]. Overall, a higher proportion of Canadian men reported all adverse health-related behaviours compared to women, with the exception of inadequate sleep. This is in contrast to previously published work, which suggests that women are at an increased risk of sleep disorders, including insomnia and lower quality sleep, and that sleep dysregulation may have more severe health consequences for women [26]. Sex-based patterns in groupings of health-related behaviours were present such that adverse behaviours cooccurred more strongly with current smoking among men and with high-risk alcohol use among women.

Fruit and vegetable intake, inadequate sleep, smoking, and inadequate physical activity all demonstrated an income and education gradient, consistent with other Canadian studies [5, 27]. The pathways between socioeconomic status and the various health-related behaviours are multiple and complex [28]. Low-income neighbourhoods may be less likely to have facilities or locations such as parks,

Table 3 Co-occurring health-related behaviours (\% (SE))

\begin{tabular}{|c|c|c|c|c|c|}
\hline Health-related Behaviour & $\begin{array}{l}\text { Smoking } \\
(22.1(1.0))\end{array}$ & $\begin{array}{l}\text { High-risk alcohol use } \\
(22.0(1.4))\end{array}$ & $\begin{array}{l}\text { Inadequate sleep } \\
(36.0(1.1))\end{array}$ & $\begin{array}{l}\text { Inadequate physical activity } \\
(17.9(0.9))\end{array}$ & $\begin{array}{l}\text { Low fruit and vegetable } \\
\text { intake }(69.1(1.3))\end{array}$ \\
\hline Smoking (1309) & - & $38.2(3.2)$ & $46.7(2.0)$ & $26.6(2.7)$ & $77.4(2.0)$ \\
\hline $\begin{array}{l}\text { High-risk alcohol } \\
\text { use (1408) }\end{array}$ & $33.2(2.0)$ & - & $40.0(2.6)$ & $19.3(1.8)$ & $73.4(1.8)$ \\
\hline Inadequate sleep (2363) & $28.6(1.9)$ & $30.3(2.5)$ & - & $20.2(1.5)$ & $68.8(2.1)$ \\
\hline $\begin{array}{l}\text { Inadequate physical } \\
\text { activity (1194) }\end{array}$ & $32.8(3.7)$ & $28.6(3.2)$ & $40.5(2.6)$ & - & $74.4(2.7)$ \\
\hline $\begin{array}{l}\text { Low fruit and vegetable } \\
\text { intake (4655) }\end{array}$ & $24.7(1.4)$ & $28.1(1.7)$ & $35.9(1.5)$ & $19.3(1.0)$ & - \\
\hline
\end{tabular}

Note: SE, Standard Error 
Table 4 Odds of health-related behaviours according to other health-related behaviours (OR (95\% CI))

\begin{tabular}{|c|c|c|c|c|c|}
\hline \multirow{2}{*}{$\begin{array}{l}\text { Health-related behaviour } \\
\text { (predictor) }\end{array}$} & \multicolumn{5}{|l|}{ Outcome } \\
\hline & Smoking & $\begin{array}{l}\text { High-risk alcohol } \\
\text { consumption }\end{array}$ & Inadequate sleep & $\begin{array}{l}\text { Inadequate physical } \\
\text { activity }\end{array}$ & $\begin{array}{l}\text { Low fruit and vegetable } \\
\text { intake }\end{array}$ \\
\hline \multicolumn{6}{|l|}{ Men } \\
\hline Smoking & - & $1.89(1.27-2.81)^{* *}$ & $1.77(1.23-2.56)^{* *}$ & $1.53(1.07-2.21)^{* *}$ & $1.56(1.02-2.39)^{*}$ \\
\hline $\begin{array}{l}\text { High-risk alcohol } \\
\text { consumption }\end{array}$ & $1.89(1.27-2.81)^{* *}$ & - & $1.22(0.87-1.71)$ & $1.22(0.87-1.71)$ & $0.98(0.75-1.28)$ \\
\hline Inadequate sleep & $1.77(1.23-2.56)^{* *}$ & $1.22(0.87-1.71)$ & - & $0.94(0.71-1.23)$ & $1.09(0.77-1.54)$ \\
\hline $\begin{array}{l}\text { Inadequate physical } \\
\text { activity }\end{array}$ & $1.53(1.07-2.21)^{* *}$ & $0.98(0.75-1.28)$ & $0.94(0.71-1.23)$ & - & $1.11(0.73-1.67)$ \\
\hline $\begin{array}{l}\text { Low fruit and vegetable } \\
\text { intake }\end{array}$ & $1.56(1.02-2.39)^{*}$ & $0.97(0.70-1.46)$ & $1.09(0.77-1.54)$ & $1.11(0.73-1.67)$ & - \\
\hline \multicolumn{6}{|l|}{ Women } \\
\hline Smoking & - & $2.06(1.19-3.56)^{*}$ & $1.12(0.70-1.78)$ & $0.95(0.56-1.61)$ & $1.31(0.90-1.89)$ \\
\hline $\begin{array}{l}\text { High-risk alcohol } \\
\text { consumption }\end{array}$ & $2.06(1.19-3.56)^{*}$ & - & $1.68(1.12-2.53)^{*}$ & $2.44(1.45-4.09)^{* *}$ & $1.54(1.01-2.34)^{*}$ \\
\hline Inadequate sleep & $1.12(0.70-1.78)$ & $1.68(1.12-2.53)^{*}$ & - & $1.57(1.07-2.31)^{*}$ & $0.83(0.63-1.09)$ \\
\hline $\begin{array}{l}\text { Inadequate physical } \\
\text { activity }\end{array}$ & $0.95(0.56-1.61)$ & $2.44(1.45-4.09)^{* *}$ & $1.57(1.07-2.31)^{*}$ & - & $1.44(1.04-2.00)^{*}$ \\
\hline $\begin{array}{l}\text { Low fruit and vegetable } \\
\text { intake }\end{array}$ & $1.31(0.90-1.89)$ & $1.54(1.01-2.34)^{*}$ & $0.83(0.63-1.09)$ & $1.44(1.04-2.00)^{*}$ & - \\
\hline
\end{tabular}

gyms or community centres that facilitate physical activity. Families may also shift towards cheaper, more energydense foods when incomes drop, often-forgoing high quality proteins, fruits, and vegetables [29]. Although it is not clear whether lower income leads to shorter, lower quality sleep or vice versa, research suggests the correlation between poverty and sleep does exist [30, 31].

The consistent and significant association between socioeconomic status and several health-related behaviours, and how they occur together, underscores the necessity of addressing social determinants of health. Consideration of these associations could potentially maximize effective, targeted interventions in low socioeconomic groups, subsequently reducing the adverse health effects of these behaviours. The need to address social determinants is further supported by growing evidence of the limited tractability of many health-related behaviours [32-34].

Alcohol use has shown a two-way relationship with socioeconomic status; risky or heavy alcohol use has been shown to predict unemployment, and unemployment increases the odds of problem alcohol use among young men in the UK [35]. Furthermore, lower lifetime income trajectories were associated with higher odds of both adult alcohol abstinence and heavy drinking in US adults [36]. The lack of socioeconomic gradient for high-risk alcohol use in the present study may be specific to the Canadian context and time period, or it may reflect the criteria used to dichotomize high- and low-risk alcohol use. Notably, high-risk alcohol use in Canada has increased over time [37].

Results from our study also reveal sex differences in the co-occurrence of health-related behaviours. Highrisk alcohol use in women demonstrated increased odds of all other adverse health-related behaviours examined in this study. This pattern did not hold true for men. To interpret these differences and conduct a SGBA [18] it is important to discuss sex and gender, and their respective influences on health-related behaviours. The sex differences observed may be related to the rise in binge drinking among young Canadian women [37], which may be driven by a number of social factors. For example, relatively recently women have experienced increased participation in the workforce and subsequently increased income [38], and cultural norms related to alcohol use for women have changed such that it is more acceptable for women to binge-drink [39]. Importantly, women are more likely to consume alcohol in response to negative emotions and stress as compared to men [40], but women also view alcohol as an important and pleasurable aspect of their social life [41].

The increasing rates of alcohol-related hospitalization of Canadian women [42] and recently published recommendations that deem no amount of alcohol is safe [43], suggest that further research examining drinking among Canadian women is needed. We have previously reported that Canadian women who report high-risk alcohol use also report better self-rated health [44], suggesting future 
avenues of research should focus on the sociological aspects to explain why women drink alcohol. A particular focus on Canadian women in the workforce may be warranted given the lack of socioeconomic gradient in highrisk alcohol use and the potential role of stress in driving these relationships between health-related behaviours.

For men, smoking was a significant predictor of all other health-related behaviours, which was not the case for women. Similar to the relationships observed with high-risk alcohol use among women, it is important to consider both sex and gender [45] in the interpretation of relationships of health-related behaviours and smoking among men. The Surgeon General's Report concluded that women who smoke are more susceptible to depression and anxiety disorders than non-smokers, and that women trying to quit smoking relapse for different reasons than men [45]. Women are more likely to use smoking as a coping mechanism for stress, weight control and negative emotions, while men who smoke do so more for stimulation and in pleasurable settings [46]. Smoking is strongly associated with alcohol use among men [47], which is, at least partially, due to increased pleasure from smoking cigarettes when consuming alcohol [48]. Neuroimaging studies also suggest that smoking activates men's reward pathways more than women's, consistent with the idea that men smoke for the reinforcing effects of nicotine [47]. Taken together, these results suggest both sex and gender differences, i.e. social differences, may be affecting different relationships between smoking and other health-related behaviours among men and women.

The different patterns of relationships between healthrelated behaviours, particularly concerning smoking or high-risk alcohol use, suggest pleasure and behaviors associated with sociability remain strong influencers of behavior, regardless of public health recommendations. Public health, when urging behavior modification or abstinence, must grapple with the legitimate value of pleasure in individuals' lives, particularly when considering issues of health equities $[49,50]$.

\section{Limitations}

The study is subject to limitations. The pooling of samples from two time periods has limitations, namely if a large change has occurred in the sample populations, for example age structure. Given the close time period of data collection between the two surveys though, any change is likely to be fairly minimal. Importantly, the survey questions that were used in the present study did not change between the two surveys. Research that is dependent upon voluntary subject participation is particularly vulnerable to sampling bias. Notably, the CHMS has a low response rate, which may have impacted the analysis reported here, specifically in terms of underestimating adverse health-related behaviours. Response bias of self-assessed behaviour has been observed in the literature, potentially resulting in underestimation in prevalence of health-related behaviours [52]. Unfortunately, we are unable to test for differences among respondents and those who did not participate, which limits our ability to speculate as to how non-response may have influenced relationships between healthrelated behaviours. The lower response rate for the questions related to alcohol use is also a limitation and may have influenced the results. Finally, all healthrelated behaviours have been dichotomized. Each healthrelated behaviour has demonstrated a dose response relationship or J-shaped relationship with a variety of health outcomes. Regardless of threshold effects, some information may have been lost through dichotomizing, such as grouping former smokers with never smokers in the non-smoker group.

\section{Conclusions}

Health-related behaviours are important because they are linked cumulatively to morbidity and mortality. Our results suggest that adverse health-related behaviours should be considered in both isolation and combination when designing health promotion policies, and further reiterates the importance of addressing social determinants of health. The gender-specific co-occurrence of healthrelated behaviours (i.e. drinking in women; smoking in men) both suggest that social interactions or pleasure may be fueled by behaviours that have a detrimental effect on the health of Canadians. A greater emphasis must be placed on the social function, interactions, and meanings of tobacco and alcohol. Affirmative, salutogenic approaches to health and structural, gender-specific interventions that facilitate positive mental and social health and alternative sources of pleasure may be necessary. Results of this study provide useful data to inform the creation and evaluation of health promotion strategies in order to achieve maximum positive health impact by individual, group and population-level approaches.

\section{Abbreviations \\ CHMS: Canadian Health Measures Survey; SGBA: Sex and gender based analysis}

\section{Acknowledgements \\ We gratefully acknowledge the Manitoba Research Data Centre data analyst Dr. lan Clara for his support in the analysis and data vetting. Although the research and analysis are based on data from Statistics Canada, the opinions expressed do not represent the views of Statistics Canada.}

\section{Authors' contributions}

NDR and ANM were involved in the design, conceptualization, analysis/ interpretation of the data, and drafting the manuscript. AEB contributed to the analysis/interpretation and was involved in drafting and revising of the manuscript. All authors have read and agreed with the material in the manuscript. We, the authors, take full responsibility for the content of the manuscript. 


\section{Funding}

Research at the Manitoba Research Data Centre is supported by funds to the Canadian Research Data Centre Network (CRDCN) from the Social Sciences and Humanities Research Council (SSHRC), the Canadian Institute for Health Research (CIHR), the Canadian Foundation for Innovation (CFI), and Statistics Canada. This study was funded through start-up funds from the University of Manitoba to NDR, as well as the Research Data Centre Research Award received by ANM. NDR is the recipient of a CIHR Early Career Investigator Award (grant \#155435). The funders had no role in the study design, data analysis, interpretation or preparation of the manuscript.

\section{Availability of data and materials}

The datasets used and analyzed during the current study are available by permission from Statistics Canada and the Canadian Research Data Centre Network.

\section{Ethics approval and consent to participate}

Data access for this study was approved by the Social Sciences and Humanities Research Council (SSHRC) and all analysis were completed in keeping with Statistics Canada protocol to ensure confidentiality and anonymity. Although the research and analysis are based on data from Statistics Canada, the opinions expressed do not represent the views of Statistics Canada.

\section{Consent for publication}

Not applicable.

\section{Competing interests}

The authors declare that they have no competing interests.

\section{Author details}

${ }^{1}$ Department of Food and Human Nutritional Sciences, Faculty of Food and Agricultural Sciences, University of Manitoba, 402 Human Ecology, Winnipeg, Canada. ${ }^{2}$ Department of Community Health Sciences, Rady Faculty of Health Sciences, University of Manitoba, 750 Bannatyne Avenue, Winnipeg, Canada. ${ }^{3}$ Department of Sociology, University of New Brunswick, Fredericton, Canada.

Received: 9 April 2019 Accepted: 23 September 2019

Published online: 24 October 2019

\section{References}

1. Ford ES, Zhao G, Tsai J, Li C. Low-risk lifestyle behaviors and all-cause mortality: findings from the National Health and nutrition examination survey III mortality study. Am J Public Health. 2011 Oct;101(10):1922-9.

2. Kvaavik E, Batty D, Ursin G, Huxley R, Gale CR. Influence of individual and combined health behaviors on total and cause-specific mortality in men and women. Arch Intern Med. 2010;170:711-8.

3. Schuit AJ, van Loon AJM, Tijhuis M, Ocké MC. Clustering of lifestyle risk factors in a general adult population. Prev Med. 2002;35(3):219-24.

4. Lynch JW, Kaplan GA, Salonen JT. Why do poor people behave poorly? Variation in adult health behaviours and psychosocial characteristics by stages of the socioeconomic lifecourse. Soc Sci Med. 1997;44(6):809-19.

5. Corsi DJ, Boyle MH, Lear SA, Chow CK, Teo KK, Subramanian SV. Trends in smoking in Canada from 1950 to 2011: progression of the tobacco epidemic according to socioeconomic status and geography. Cancer Causes Control. 2014;25(1):45-57.

6. Paul C, Tzelepis F, Bisquera A, Noble N, Wiggers J. Just how high-risk are ongoing smokers? Exploring clusters of health risk behaviours among current and ex-smokers. Prev Med. 2016;93:70-5.

7. Dallongeville J, Marecaux N, Fruchart JC, Amouyel P. Cigarette smoking is associated with unhealthy patterns of nutrient intake: a meta-analysis. J Nutr. 1998; 1;128(9):1450-1457.

8. Pate RR, Heath GW, Dowda M, Trost SG. Associations between physical activity and other health behaviors in a representative sample of US adolescents. Am J Public Health. 1996 Nov;86(11):1577-81.

9. Silva JP. Mapping unhealthy behavior among economically active men using GIS in suburban and rural areas of Sri Lanka. Asia Pac J Public Health. 2016;28(1 suppl):10S-6S.

10. Poortinga $W$. The prevalence and clustering of four major lifestyle risk factors in an English adult population. Prev Med. 2007;44(2):124-8.
11. Braveman P, Gottlieb L. The social determinants of health: it's time to consider the causes of the causes. Public Health Reports. 2014;(1_suppl2): 19-31.

12. Tremblay M, Wolfson M, Connor SG. Canadian health measures survey: rationale, background and overview. Health Rep. 2007;18:7-20.

13. Statistics Canada. Canadian health measures survey (CHMS) data user guide: cycle 3. 2014. http://www23.statcan.gc.ca/imdb-bmdi/instrument/5071_Q1_ V3-eng.pdf . Accessed 28 Nov 2018.

14. Statistics Canada. Canadian Health Measures Survey (CHMS). 2014. Available at: http://www23.statcan.gc.ca/imdb/p2SV.pl?Function=getSurvey\&ld=14876 0. Accessed 28 Nov 2018.

15. Courtney KE, Polich J. Binge drinking in young adults: data, definitions, and determinants. Psychol Bull. 2009;135(1):142.

16. American Heart Association. Fruits and Vegetable Servings Sizes. 2019 Available at: https://www.heart.org/en/healthy-living/healthy-eating/ addcolor/fruits-and-vegetables-serving-sizes. Accessed 5 Nov 2018.

17. Cappuccio FP, D’Elia L, Strazzullo P, Miller MA. Sleep duration and all-cause mortality: a systematic review and meta-analysis of prospective studies. Sleep. 2010;33:585-92.

18. Canadian Institutes of Health Research. What is Gender? What is Sex? 2014. Available at: http://www.cihr-irsc.gc.ca/e/48642.html. Accessed 3 Sept 2019.

19. Lee DS, Chiu M, Manuel DG, Tu K, Wang X, Austin PC, Mattern MY, Mitiku TF, Svenson LW, Putnam W, Flanagan WM. Trends in risk factors for cardiovascular disease in Canada: temporal, socio-demographic and geographic factors. CMAJ. 2009;181(3-4):E55-66.

20. Walker PL, Cook DC. Brief communication: gender and sex: vive la difference. Am J Phys Anthropol. 1998;106(2):255-9.

21. Haslanger S. Gender and race: (what) are they? (what) do we want them to be? Noûs. 2000;34(1):31-55.

22. Torgrimson BN, Minson CT. Sex and gender: what is the difference? J Appl Physiol. 2005;99(3):785-7.

23. Institute of Medicine. Exploring the biological contributions to human health: does sex matter? Washington, DC: National Academy Press; 2001.

24. Johnson JL, Greaves L, Repta R. Better science with sex and gender: facilitating the use of a sex and gender-based analysis in health research. International Journal for Equity in Health. 2009;8(1):14.

25. Statistics Canada. Canadian Health Measures Survey (CHMS). https://www. statcan.gc.ca/eng/survey/household/5071. Accessed 30 Oct 2018

26. Mong JA, Cusmano DM. Sex differences in sleep: impact of biological sex and sex steroids. Philos Trans R Soc Lond B Biol Sci. 2016;371(1688):20150110.

27. Riediger ND, Shooshtari S, Moghadasian MH. The influence of sociodemographic factors on patterns of fruit and vegetable consumption in Canadian adolescents. JADA. 2007 Sep 1;107(9):1511-8.

28. World Health Organization. A conceptual framework for action on the social determinant of health. Available at: https://www.who.int/ sdhconference/resources/ConceptualframeworkforactiononSDH_eng.pdf. Accessed 12 Nov 2018

29. Drewnowski A, Eichelsdoerfer P. Can low-income Americans afford a healthy diet? Nutr Today. 2010;44(6):246.

30. Buckhalt JA And El-sheikh M. Sleep and Poverty Available at: https:// www.apa.org/pi/ses/resources/indicator/2013/11/sleep-poverty.aspx. Accessed 10 Nov 2018.

31. Patel NP, Grandner MA, Xie D, Branas CC, Gooneratne N. " Sleep disparity" in the population: poor sleep quality is strongly associated with poverty and ethnicity. BMC Public Health. 2010;10(1):475.

32. Kelly MP, Barker M. Why is changing health-related behaviour so difficult? Public Health. 2016;136:109-16.

33. Kirkland R, Raphael D. Perpetuating the utopia of health behaviourism: a case study of the Canadian Men's Health Foundation's Don't change much initiative. Soc Theory Health. 2018;16(1):1-19.

34. Carey G, Malbon E, Crammond B, Pescud M, Baker P. Can the sociology of social problems help us to understand and manage 'lifestyle drift'? HPI. 2016;32(4):755-61.

35. Jones $L$, Sumnall $H$. Understanding the relationship between poverty and alcohol misuse. Liverpool: Liverpool John Moores University; 2016. p. 9-17.

36. Cerdá M, Johnson-Lawrence VD, Galea S. Lifetime income patterns and alcohol consumption: investigating the association between long-and short-term income trajectories and drinking. Soc Sci Med. 2011;73(8):1178-85.

37. Bulloch AG, Williams JV, Lavorato DH, Patten SB. Trends in binge drinking in Canada from 1996 to 2013: a repeated cross-sectional analysis. CMAJ open. 2016;4(4):E599. 
38. Statistics Canada. Insights on Canadian Society. Available at: https:// www150.statcan.gc.ca/n1/pub/11-630-x/11-630-x2015009-eng.htm. Accessed 10 Nov 2018.

39. Young AM, Morales M, McCabe SE, Boyd CJ, D'ARCY HANNAH. Drinking like a guy: frequent binge drinking among undergraduate women. Substance Use \& Misuse. 2005;40(2):241-67.

40. Greenfield SF, Back SE, Lawson K, Brady KT. Substance abuse in women. Psychiatr Clin. 2010;33(2):339-55.

41. Bancroft A. Drinking with and without fun: female students' accounts of pre-drinking and club-drinking. Sociol Res Online. 2012;17(4):1-11.

42. Canadian Institute for Health Information. Updated May 31, 2018. Alcohol harm on the rise for Canadian women. https://www.cihi.ca/en/alcoholharm-on-the-rise-for-canadian-women. Accessed 30 May 2019

43. GBD 2016 Alcohol Collaborators. Alcohol use and burden for 195 countries and territories, 1990-2016: a systematic analysis for the Global Burden of Disease Study 2016. The Lancet. 2018;392:1015-35.

44. Riediger, N.D., Bombak, A.E. and Mudryj, A.N., 2019. Health-related behaviours and their relationship with self-rated health among Canadian adults. BMC public health, 19(1), p.960.

45. US Department. Of health and human services. The health consequences of smoking - 50 years of progress: a report of the surgeon General. Atlanta, GA: US Department of Health and Human Services, Centers for Disease Control and Prevention, National Center for Chronic Disease Prevention and Health Promotion, office on smoking and. Health. 2014 Nov:27:17.

46. Gubner NR, Thrul J, Kelly OA, Ramo DE. Young adults report increased pleasure from smoking cigarettes when drinking alcohol but not when using marijuana. Addict Res Theory. 2018;26(1):71-6.

47. National Institute on Drug Abuse. Tobacco, Nicotine and E-Cigarettes. Available at: https://www.drugabuse.gov/publications/research-reports/ tobacco-nicotine-e-cigarettes/are-there-gender-differences-in-tobaccosmoking. Accessed 11 Nov 2018.

48. Coveney J. Human vulnerabilities, transgression and pleasure AU Thompson, Lee. Crit Public Health. 2018;28(1):118-28.

49. Prochaska JJ, Spring B, Nigg CR. Multiple health behavior change research: an introduction and overview. Prev Med. 2008:46(3):181-8.

50. Rosenman R, Tennekoon V, Hill LG. Measuring bias in self-reported data. International journal of behavioural \& healthcare research. 2011;2(4):320.

\section{Publisher's Note}

Springer Nature remains neutral with regard to jurisdictional claims in published maps and institutional affiliations.

Ready to submit your research? Choose BMC and benefit from:

- fast, convenient online submission

- thorough peer review by experienced researchers in your field

- rapid publication on acceptance

- support for research data, including large and complex data types

- gold Open Access which fosters wider collaboration and increased citations

- maximum visibility for your research: over $100 \mathrm{M}$ website views per year

At $\mathrm{BMC}$, research is always in progress.

Learn more biomedcentral.com/submissions 